\title{
Ecological Advertising: What Impact on Responsible Consumption in Morocco?
}

\author{
Amina Aomari \\ Mohammed V University in Rabat \\ Email: a.aomari@um5s.net.ma
}

\section{Doi:10.5901/mjss.2016.v7n4p}

\begin{abstract}
The multiplication of messages about environment has led to a general awareness on the stakes in protecting the environment and made the ecological theme a current issue in advertising. Considering the development of the responsible consumption in Morocco, it is interesting to wonder about the role of the ecological advertising in motivating and urging the consumers to choose friendly environment products. This paper aims to analyze the tendency of advertising executives in Morocco who use in the advertising straight forward ecological arguments as a marketing strategy. This becomes a current practice in the contents of advertising in Morocco in relation to the environmental problem. This leads to an progressive approach to improve the relevance of the advertising discourse regarding protecting the environment and its impact on the perception of the consumers who are more suspicious about the phenomenon of "Green Washing", and its impact on their attitude towards the product and the advertiser.
\end{abstract}

Keywords : Green Marketing, Ecological Advertising, Green Washing, Responsible Consumption

\section{Introduction}

Since the nineties, the performances of companies do not judge themselves any more in simple terms of profitability, but also with regard to their behavior towards people and the environment. Under the pressure of the ecologist and consumerist movements, companies have to fit from now on more into the society and become citizens.

Nowadays, companies integrate more and more sustainable development on their advertising campaigns. They try to inform directly their consumers about the ecological value of their products or their working conditions, and support projects of development and environmental protection.

We so notice an ecological rise of the concerns which widely developed to which the advertising world adapted itself. Indeed, the ecological theme is recurrent in the advertising and the ecological argumentation is used more and more openly by the campanies to attract the customer.

The consumers are at present more and more made sensitive in the protection of their environment with regard to products and services which threaten it. The bought product becomes the means to adopt an environment-friendly behavior.

The ecology is also often associated with the identity of the product, whether it is by a naming or a color which evokes strongly the environment. It thus became a real criterion of choice which has its importance.

More and more advertisements make an unfair and deceitful use of the ecological argument. This misuse deceives the consumer on the reality of the product and comes against the efforts supplied to incite him to consume in a more responsible way.

This paper is interested in the problem of the credibility of the advertisements which use the ecological arguments, a tendency which increasingly developed in Morocco. It also has for objective to estimate the perception of the Moroccan consumers and their attitude to the product and the announcer given the multiplication of the cases of "green Washing".

\section{The Consumer and the Ecology}

The multiplication of the environmental messages led to a general awareness on the ecological urgency. The environment being in the heart of the concerns of all, the consumer is little by little inclined to consume products and services having an impact reduced on the environment, and towards companies having an environmental approach. Even some authors speak about notion of solidarity which intervenes in the behavior of the ecological consumer (ThierrySeror, 1996).

Dodds, Monroe and Grewal (1991) describe consumers' purchase intentions as the possibility of a consumer's 
willingness to purchase a specific product. The interest tuned to "greens products" extended during these last years and expects to grow even more in a near future (Morris, Hastek and Mazis, 1995). The consumer became aware, today, of the stake in the sustainable development and militates for having the possibility of choosing the most environmentfriendly products in their phase of production, consumption or recycling.

\subsection{The emergence of the responsible consumption}

According to Lahaye (1995), it is possible to define the ecological consumption as " a thoughtful consumption which takes into account the impact which it exercises on the environment ".

Some brands have create a signature or an environment label distinguishing some of their products or lines. Even brands do not only try any more to convey only the image of their products but also want to build their own image and position vis à vis their competitors (Fady and Pontier, 1999).

We notice more and more a strong consumer trend to look for the ecologically correct. On the basis of their relationship in the responsible consumption, there are several typologies of consumers who differ by the degree of implication, their motivations and the brakes which limit their ecological actions. A responsible consumer is the expression of a warned, responsible and committed consumer who has to encourage the best practice of consumption and denounce the bad one.

According to Rochefort (2001), the consumer, who needs from now on to be reassured, becomes more and more sensitive to the health, the ecology and the humanitarian work.

The environment is a thorough effect which will not disappear (Zaccai, 2011). The concern for the environment consists of two dimensions : the attitude of the consumer expressing an interest for the ecology and the adoption of a coherent purchasing behavior with the preservation of the systems (Kinnear, Taylor and Ahmed, 1974).

We can consider the green consumer as the one who takes into account the consequences which his purchases can have on the society and the environment (Webster, 1975). The demographic composition of green consumers changed during the last decade the attention given by the media to environmental issues and because the environmental deterioration affected the the consumers of lower socioeconomic levels who's become involved (Robert, 1996).

Several studies concerned the realization of a typology of the consumers behavior regarding sustainable development and regarding environment by analyzing their perception and attitudes regarding environmental protection, fight against pollution and economy of resources actions (Center of research and Information of the Consumers associations, 2003)

Thorson, Page and Moore (1995) and Davis (1994) confirm the persuasive efficiency of using an ecological call. This can be understandable by the increasing awareness of the environmental problems (Stafford, Stafford and Chowdhury, 1996). This awareness is in favour of the pro-environmental behavior (Balderjahn's, 1988) and the purchase of the ecological products (Schwepker and Cornwell, 1991).

The environmental knowledge of a consumer is positively moved closer to its intention to buy the product (Manrai, Manrai, Lascu and Ryans, 1997). Furthermore, several studies showed that the more the consumer is durably involved to the ecological products, the more he will, on one hand, tend to develop a favorable attitude to the green advertising and the brand concerned (Schuhwerk and Lefkoff-Hagius, 1995; D' souza and Taghian, 2005) and, on the other hand, to intend to buy the ecological products (Schuhwerk and Lefkoff, 1995).

The marketing has a great role to play in the sustainable development (Sempels and Vandercammen, 2009). Informing about the ecological qualities of a product or service and inciting to a more responsible consumption in this domain is fundamental.

\subsection{The lack of information : brake in the responsible purchase}

A responsible consumer has to inquire about the origin of what he consumes. He has to have access to a neutral information, non oriented by economic interests, which allows to maintain its critical mind and to choose in full knowledge of the facts.

However, according to 2000 OECD report, "One of the major purchase difficulties is the lack of available and reliable information on the environmental characteristics of products and services. In fact, this lack of information is sometimes considered as the main obstacle to the initiatives of more green purchases ".

Verify if a product or a service presents effectively the asserted environmental qualities require knowledge which few consumers have. The level of information of the consumer is insufficient (Boulstridge and Carrigan, 2000, Mohr, Webb and Harris, 2001, Auger, Burke, Devinney and Louvière, 2003). For Carrigan and Attalla (2001), several 
consumers are not conscious of ethical stakes in the consumption, and sensitization would bring them to integrate the ethics into their choice of consumption.

Nowadays there are numerous peculiar labels to every sector which guarantee quality levels according to specifications to be respected. These indicators are different according to the business sectors and it is possible to find it various in every sector. Facing this multiplication of indicators, the consumer risks to be lost and not to know any more on which logo he has to rely.

Furthermore, it seems harder and harder to make the difference between the labels which are controlled by certification bodies and those who are set up by the industrialists without necessarily of objective controls.

The consumer finds himself submerged by all kinds of ecological declarations and does not know how to estimate any more the information which we supply him (Teisl and Levy, 2003). Time constraints, budgetary constraint, lack of "responsible" products and their weak availability and problems of information also return the consumer towards the complicated and too binding environment (Lecompte, 2003) and constitute brakes in the responsible purchase.

\section{The Progression of the Environment in the Advertising Universe}

The advertising pollutes not only the urban and rural landscapes, but also the mentalities (Löwy and Rodary, 2010). The choice of the environment as new advertising strategy thus implies company to a reformulation of the message following new principles and new variables, the environmental protection being the main idea for which the company would try to convey.

\subsection{The ecological advertising : a new tendency}

In conditions of very keen competition of the world economy of today, insuring an environmental reputation is of a crucial importance for the commercial success of any company. Companies owe be transparent and agree to be accountable in their stakeholders (Laville, 2009). They have to acquire a label of legitimacy (Dubigeon, 2005).

The advertising has to answer new expectations, those of consumers in search of sense, of transparency and of ethics as well as those NGO and governments, which ask to inform, to alert and to arouse responsible behavior concerning the problems threatening the planet.

We can consider as ecological any advertising, independently of the degree of credibility which can be associated with, which refers to the effects of a product or a service on the environment during their life cycle, whatever is the used support.

It is a question of creating a connection between the product and the nature in consumer mind. So, slogans, images and photos of advertisements convey ideas which evoke the environmental protection and the sustainable development.

The ecological argument is any claiming, indication or presentation, in any form whatsoever, used in main or secondary title, establishing a connection between the brands, the products, the services or the actions of an announcer, and the environmental protection (Authority of Advertising Professional Regulation, 2009).

However, this advertising strategy must not be thoughtlessly chosen because it engage the company on its purpose and on its morality, as well as it implies the respect for multiple commitments to her customers, the society and even the government.

It happens that advertising declarations concerning an approach of the sustainable development concern just the environmental component. However, the advertising cannot express a global promise regarding sustainable development if the commitment of the announcer does not concern concurrently three pillars of the sustainable development (Authority of Advertising Professional Regulation, 2009).

With the importance of the new stakes which the announcers have to face, the United Nations Environment Programme (UNEP) set up, from 1999, the Forum on the advertising and the communication the objective of which is to make sensitive the actors of this sector (announcers, advertising agencies and media) in problems bound to the sustainable development and to supply ways of reflection to develop a communication better adapted to the new consumer expectations.

Several studies were interested to study the impact of the advertising using an ecological argument on the consumer behavior (Schuhwerk and Lefkoff-Hagius 1995, Zinkhan and Carlson 1995, Stafford, Stafford and Chowdhury 1996, Libaert 1992). However, these studies were in the majority realized in countries as France and the USA. The importance of the ecological advertising being confirmed by these works, it would be then discerning to know what extent the presence of an ecological call in the advertising could influence the behavior of the Moroccan consumer. 
The communication of companies indeed exercises a significant influence on attitudes and consumer behavior in an emergency context environmental marked (Benoit-Moreau, Parguel and Larceneux, 2008).

The announcer has to be capable of justifying the advertising arguments concerning the sustainable development by means of serious, objective and verifiable elements. The technical, scientific or legal vocabulary, can be used if it is suited and understandable for the people whom the advertising message is addressed.

The advertising message has to express aptly the action of the announcer or the properties of its products, in adequacy with the justificatory elements which it has. The advertising message must be proportionned in the scale of the actions led by the announcer regarding sustainable development as well as to the properties of the product which it makes the promotion.

An advertising campaign with ecological content having no real assizes within the broadcasting company will only succeed in swindling the ecological consumers without producing in the best case any beneficial impact for the environment (Lahaye, 1995).

\subsection{The unfair use of the ecological argument in the advertising : The Greenwaching}

"The advertising style consists in claiming the protection of what we contribute to destroy" (Bénilde, 2008).

More and more advertisements use wrongly the ecological argument to praise " as voucher for the environment " activities and products in reality polluting or which the ecological balance assessment is negative. The consumer has the erroneous impression that the use and the consumption of these products are advantageous for the environment, while in reality, they are simply less harmful than comparable products which are of use to the same purposes (Sabourin, 2002).

The greenwashing is the word used collectively when a message of communication deceives or uses ill-advisedly the ecological argument. It serves to evoke the abuse of advertising or ecological arguments by companies or organizations which want to show the environmental virtues with the aim of taking advantage of positive effects generated by an attitude turned to the environment.

This is the case when a product or service is boasted as "green", "protecting nature and the environment", while the interest of product or service to the environment is minimal or nonexistent. It's the same for company, boasted as committed to sustainable development, but overall activity is recognized as problematic from an environmental point of view.

"Greenwashing" can also put forward a particular point of suggesting that the product brand is eco-friendly, while leaving a shadow on the manufacturing processes or elements of composition much less bright areas. Newell, Goldsmith and Banzhaf (1998) define it as "misleading advertising".

Several movements, associations and NGOs campaigning for better and real consideration of the environment by requiring businesses and advertisers to respect the law and their own environmental ethics.

The truth of the contents of the advertisement can not be verified by an environmental consumer who is not an expert in the assessment of environmental impacts associated with the production of goods or the provision of a service. This is why eco-consumers, so they can feel confident face an environmental statement, have much higher requirements regarding guarantees of independence and credibility to an advertisement for the quality or usefulness of a product (Cohen 1991 and Boeglin Nadai 1998).

It seems that public denunciation of different cases of "greenwashing" has affect the credibility of environmental advertising in general (Coddington, 1993).

Several authors have provided various examples of cases where a company that was displayed, with advertising slogans of all kinds, such as "green" could not justify his statements environmental preference (Tanguay 1996, Johnson 2004 , Hoch and Franz 1995).

The most affected sectors by the misuse of the ecological argument in advertising are the automotive and consumer goods. Indeed, the ads touting green properties cars continue to multiply. It is especially automakers that use ecological argument to increase their sales. This is the case of the "green premium" that correspond to premiums recovery of old vehicles that have existed for a long time and had not an environmental objective.

Any form of environmental advertising is not fundamentally designed to deceive consumers. Some authors consider that the majority of advertising content to environmental claims are made in "good faith" (Coddington 1993 and Marchand 1995).

So as not to mislead consumers about the ecological reality of the product, advertising must be truthful, objective, proportionate to reality, using a fair and sufficiently clear and precise terminology.

In terms of advertising language, it refers to the use of expressions such as "contributing to" or "participate in", specifying the nature of the contribution or participation (Agency for Environment and Energy Management, 2007). 


\section{Ecological Advertising and Moroccan Consumers}

Nowadays, there is a real awareness of the importance of the environmental aspects and more companies are looking more to join. Like most developing countries, Morocco is expected to adhere to the culture of environmental responsibility and communicate it.

In this sense, several developing countries have opted for advertising to inform on their behaviors and commitments to the environment. These practices were imposed by multinational companies operating in these countries in the institutional, legal, social and economic specific context.

Moreover, in developing countries, environmental regulations in many cases, is still under construction or in its infancy. There are no specific standards for each sector.

Because of the openness to Europe and globalization, the lifestyle of the Moroccan consumer has changed a lot in its economic and cultural dimensions.

In Morocco, the concept of ecology in the marketing and communication strategy is being developed, it is just beginning to take off in the world of Moroccan advertising. Associations of environmental groups argue in this direction and Moroccan consumer begin to understand and respect the environment and sustainable development concept.

Many green products present and distributed in Morocco comes from foreign, especially French companies, some of which are certified by an official Ecolabel : the European Eco-label.

In Morocco, sustainable development is still unknown to the general public. As in most developing countries, the Moroccan consumer is more attracted by the quality / price ratio that the conditions under which the product was produced.

\subsection{Research Methodology}

Our methodology is based on a review of the literature and the press, supplemented by observations made in the field and an analysis of advertisements addressing an environmental aspect of a product or service sold in Morocco. The analysis focuses on advertising and the products or services promoted by advertising messages. The studied media are Television, billboards and the press and the period covered by the study is from July to December 2012.

We conducted a survey of advertising agencies. Data were collected at several semi-structured interviews conducted with designers - editors, art directors and directors of studies to approach ecological advertising through people that are involved everyday.

A transcript of the interviews were conducted and content analysis was done manually. It is materialized through a thematic analysis with sorting, classification and categorization of the themes identified.

Meanwhile, we conducted a survey of a sample of consumers composed mainly of students on higher education in Morocco. The age, income and level of education affect the transaction and societal sensitivity of consumers (Binninger 2006). This choice is justified by the fact that the concept of an engagement for sustainable development is still in its infancy in Morocco and the means used to there are not accessible to all socio-professional categories. It was also made in relation to an opportunity to access the data.

Participants in this study were selected through a convenience sampling method. The survey questionnaire was divided into three sections. The first section contained questions/statements on the variables in the conceptual framework especially consumer behavior towards the sustainable development, the second section contained questions/ statements about ecological advertising and the phenomenon of green washing in morocco while the third section contained questions/statements on the respondents' background (age, gender, income level and education level). Likert scale was used to measure the items.

Young people are most affected by advertising. However, they are more sensitive to business practices, and able to decrypt messages. The interviewed students watch a lot of publicity and some of them are more concerned about the participation by a course on creative advertising. The response was voluntary.

Likert scale was used to measure the items. We conducted a pilot study to examine the face validity of the questionnaire (Sekaran, 2003). Some of the questions that appeared confusing or irrelevant were revised and the questionnaire was updated accordingly. we analyzed data collected using the statistical software "SPHINX", which allowed us to achieve significant results in tabular form with single input (tri flat) and double input (cross-tabulation of target variables).

Our analysis is not based on a representative statistical sample, but more about what Glaser and Strauss (1967) call a "theoretical sample".

We tried to examine the influence of advertising execution elements, namely the use of the green color and the 
word "green" and / or "sustainable" on consumer perceptions and attitudes toward the product and the advertiser taking into consideration each time the clarity and accuracy of the message information.

The measurement scales used are sustainable involvement, brand attitude, attitude toward the advertising and purchase intention.

\subsection{Findings and Recommendations}

The survey highlight the use of ecological argument in advertising, sectors and companies using the most ecological argument or sustainable development and the types of products and services most affected by the ecological argument.

The sector using more environmental advertising in Morocco is the automotive sector particularly with the entry of the hybrid car in Morocco, followed by some consumer products including food products from organic agriculture.

We can deduce that in Morocco, ecology and sustainable development are still some lines of communication used by the advertisement.

The study reveals that the Moroccan consumer is more sensitive, but also affected by environmental concerns and displays a more favorable attitude towards environmental advertising. When asked if they were ready to act to protect the environment, a large majority of respondents say they are willing to change their lifestyle and pay a little more for products that respect the environment.

However, advertising focuses on an ecological argument has no effect on the purchase intention of the Moroccan consumer who remains dependent on several other factors such as social status, purchasing power, income and education.

The survey also highlights the moderating effect of consumer involvement in sustainable environmental advertising and consumer purchase intention relationship.

Beyond promoting their brand, some companies in Morocco are seeking to contribute to the public awareness of some eco-citizen without obscuring the reality of the environmental impact of the company and its business.

Consumers also said they were less confident to almost all of the environmental information sources. Respondents leave little fooled by greenwashing practices and largely uninvolved in the development of solutions to this "new phenomenon." They say that they must come from specific actors such as producers, distributors and government.

This feeling that consumption should be an important element of sustainable development seems to be growing in Morocco. Awareness programs were launched by the government and consumer participation in these programs appears to be widespread.

The Moroccan consumers hesitate between money and awareness. The results show that the factors that influence the Moroccan consumers in their purchasing behavior is primarily the price, then the quality of products and services and finally the ecological cost.

The acts that require a financial commitment like buying labeled products are much less adopted. Efforts still need to be done in terms of preference for products that respect the environment.

While consumers may be seduced by green offers, they are aware that some companies are taking advantage of the ecological trend simply to expand their sales. They want the "green" messages are approved by an independent and strict control authority.

Indeed, the majority of respondents believe that companies do not give them enough information on the conditions of manufacture of their products. They want more information on corporate engagement in information campaigns to encourage green behavior.

They also find that existing indicators to report "green" products are not sufficiently, the consumer does not have all the necessary information for the direct purchase, which seems in total contradiction with the development of responsible consumption.

According to the study, and contrary to expectations, or the use of green color on the visual advertising or the use of the term "sustainable" would have no direct impact on consumer perceptions in terms of image of the product or the advertiser.

\section{Suggestions}

The main suggestions that emerge from this study focus on the establishment of a code of environmental advertising with the introduction of a system of effective control of advertising activities. The code should protect consumers against abusive exploitation of his concern for the environment.

Like the developed countries, the code should apply to any advertisement referring to the environmental impact of 
a product regardless of the medium used during their life cycle.

An agreement with producers, distributors and advertising professionals, should be reached on the one hand and consumers and the environmental movement, on the other for the creation of an official label based on specific, credible and verifiable criteria.

It is very important that the environmental benefit is qualified and properly explained so that consumers can not be misled about the reality of this advantage.

It should also be stricter rules on advertising in terms of sustainable development and better manage the use of environmental claims in advertisements to enhance the credibility of the information released, strengthen consumer awareness and restore confidence in advertising.

\section{Conclusion}

The protection of the environment can not be done in Morocco through advertising ecology only. It is important to note that the Moroccan behavior must adapt to new environmental data to adopt healthy behavior. Awareness is the safest way to get there.

The word "sustainable" is more associated in the public mind to what is environmentally friendly, it is questionable whether some uses of the term will not create confusion in people's minds. It is clear that the environmental performance of an act of ecological consumption depends largely on the quality of information on which the buyer is founded to provide a good or service, friendly environment.

It seems that the rise of the green consumption in Morocco and therefore sustainable development necessarily involves a tightening of legal rules to control the accuracy of environmental claims in general.

Changing habits is a social process that will take years. It involves a real change must focus on educational activities and control of consumer, environmental and government movements.

This study was limited to a sample of students on higher education in Morocco. Future research should expand the sample to include other occupational categories that are more representative of the population.

The implications of this study suggest that marketers wishing to promote their products and services have to target people who are already active and even heavily involved in environmental causes.

\section{References}

Auger $P$, Burke $P$, Devinney T M and Louvière J J, (2003), What will consumers pay for social product features, Journal of Business Ethics, 42, 3, 281-304

Balderjahn I, (1988), Personality Variables and Environmental Attitudes As Predictor of Ecologically Responsible Consumption Patterns, Journal of Business Research, 17, 51-56.

Bénilde M, (2008), We buy good brains. Advertising and media, Raisons d'agir.

Benoit-Moreau F, Parguel B et Larceneux F, (2008), How to prevent greenwashing ? The influence of advertising execution elements, Cahier de Recherche DMSP, $n^{\circ} 379$.

Binninger AS, (2006), « Consumer paradoxes at the heart of marketing stakes - an analysis of transactional and societal sensitivities », Actes du 6ème Marketing Trends Conference, Venise, Italie.

Boeglin N, (1998), « Life cycle analysis : Promoting the ecological quality of products and ecolabels » ENSTIB.

Boolstridge E and Carrigan M, (2000), Do consumers really care about corporate responsability ? Highlighting the attitude-behaviour gap, Journal of Communication Management, 4, 4, 355-368.

Carrigan M and Attalia A, (2001), The myth of ethical consumer - do ethics matter in purchase behavior ?, Journal of Consumer Marketing, 18, 7, 560-577.

Centre de Recherche et d'Information des Organisations de Consommateurs, (2003), «Consumers, environment and sustainable development. Typology of perceptions», Ministère de l'Environnement, Belgique.

Coddington W. (1993), Environmental Marketing: Positive Strategies for Reaching the Green Consumer. McGraw- Hill.

Cohen D S, (1991), «The regulation of green advertising: The State, the market and the environmental good», University of British Columbia, Law Review, 225- 240.

D'Souza C and Taghian M, (2005), "Green advertising effects on attitude and choice of advertising themes", Asia Pacific Journal of Marketing and Logistics, 17, 3, $51-66$.

Davis J J, (1994), "Consumer Response to Corporate Environmental Advertising," Journal of Consumer Marketing, 11, 2, 25-37.

Dodds B.K, Monroe K.B and Grewal D, (1991), Effect of price, brands and store information on buyers' product evaluation. Journal of Marketing Research, 28(3), 307-319;

Dubigeon O, (2005), Practicing sustainable development: what processes for responsible company ? Village Mondial.

Environment Agency and the Energy Control, (2007), «Is the advertising respectful of sustainable development ? », Association des Professionnels pour une Publicité Responsable, France. 
Fady A et Pontier S, (1999), Are consumers sensitive to ecological actions of Hypermarkets and supermarkets ?, Revue Française de Marketing, 175, 5, 93-105.

Glaser BG and Strauss A, (1967), Discovery of Grounded Theory. Strategies for Qualitative Research, Adlineage Publications, Sociology Press.

Hoch D and Franz R, (1995), «Eco-porn versus the Constitution: Commercial Speech and the Regulation of Environmental Advertising», Albany Law Review, 58, 441-461.

Johnson G, (2004), Don't be fooled: The ten worst greenwashers of 2003, Green life.

Kinnear T C, Taylor JR and Ahmed SA, (1974), «Ecologically concerned consumers : Who are they? », The Journal of Marketing, 38, 2, 20-24.

Lahaye M.-C (1995), "The consumer and green products », Écodécision, 60-62.

Laville $\mathrm{E},(2009)$, Green business : Sustainable development changes the company to change the world, Village Mondial.

Lecompte F A, (2003), Towards a better understanding of socially responsible consumption, Actes du congrès de l'Association Française de Marketing,Tunis.

Libaert T, (1992), The green communication: Ecology at company service, Editions Liaisons.

Löwy M et Rodary E, (2010), « Advertising seriously damages health of the environment, Écologie et Politique, 39, 13 -23.

Manrai L A, Manrai A K, Lascu D N and Ryans J K Jr, (1997), How green-claim strength and country disposition affect product evaluation and company image, Psychology \& Marketing, 14, 511-537.

Marchand J, (1995), « Environnemental marketing » dans Brûlotte R, dir, Environnement, Économie et entreprise, Sainte-Foy, TéléUniversité, Presses de l'Université du Québec.

Mohr L A, Webb D J and Harris KE, (2001), Do consumers expect companies to be socially responsible ? The impact of corporate social responsability on buying behavior, Journal of Consumer Affairs, 35, 1, 45-72.

Morris L, Hastak M and Mazis A, (1995) « Consumer comprehension of environnemental advertising and labeling claims», Journal of Consumer Affairs, 29,2,328-350.

Newell S.J, Goldsmith R.E and Banzhaf E.J, (1998), The effects of misleading environmental claims on consumer perceptions of advertising, Journal of Marketing Theory and Practice, 6, 2, 48-60.

Professional Regulatory Authority of advirtising, (2009), « Recommendation sustainable development », Association des Professionnels pour une Publicité Responsable, France.

Roberts J A, (1996), Green consumers in the 1990s : Profile and implications for advertising, Journal of Business Research, 36, 217231.

Rochefort R, (2001), The consumer society, Odile Jacob.

Sabourin C, (2002), «Rethinking consumption patterns for the well-being of present and future generations », Énergie LiaisonFrancophonie.

Schuhwerk M and Lefkoff-Hagius R, (1995), "Green or non green? Does type of appeal matter when advertising a green product?", Journal of Advertising, 24, 2, 45- 54.

Schwepker CH and Cornwell T B, (1991), An Examination of Ecologically Concerned Consumers and Their Intention to Purchase Ecologically Packaged Products, Journal of Public Policy and Marketing, 10, 2, 77-101.

Sekaran U and Bougie R, (2003), Research Methods for Business, A skill Building Approach, New York Holt.

Sempels C et Vandercammen M, (2009), Dare sustainable marketing, Pearson Education

Stafford M R, Stafford T F and Chowdhury J, (1996), Predispositions toward green issues : The potential efficacy of advertising appeals, Journal of Current Issues and Research in Advertising, 18, 67-79.

Tanguay F, (1996), « Greenwashing and Sustainable Development: business meet the challenge ? », Actes du Colloque Entreprise et développement durable : opérationnaliser le développement durable au sein de l'entreprise, Montréal, ACFAS.

Teisl M F, Roe B and Levy A S, (2003), «Ecolabeling : What Does Consumer Science Tell Us about which Strategies Work?» dans Lockeretz W, Ecolabelling and the greening of the food market, Boston, Université de Tufts, 148- 149.

Thierry-Seror P, (1996), Solidarity through the products : the purchase-ecological gesture, Actes du Congrès de l'Association Française de Marketing, Poitiers, 107-123.

Thorson E, Page T and Moore J, (1995), Consumer response to four categories of "green" television commercials, Advances in Consumer Research, 22, 243-250.

Webster F E, (1975), Determining the Characteristics of the Socially Conscious consumer, Journal of Consumer Research, 2, 188-196.

Zaccai E, (2011), "25 years of sustainable development, and after ?", PUF.

Zinkhan G M and Carlson L (1995), "Green Advertising and the Reluctant Consumer," Journal of Advertising, 24, 2, 1-6. 